\title{
Cardiopulmonary bypass and cancer dissemination and progression: myth reality, enigma, puzzle?
}

\author{
Li Siyuan ${ }^{1}$, Danilo Tadao Wada ${ }^{2}$, Paulo Roberto Barbosa Evora ${ }^{1}$ \\ ${ }^{1}$ Department of Surgery and Anatomy of Ribeirao Preto Medical School FMRP-USP, University of São Paulo, São Paulo, Brazil; ${ }^{2}$ Department of \\ Medical Imaging, Hematology and Oncology of Ribeirao Preto Medical School FMRP-USP, University of São Paulo, São Paulo, Brazil \\ Contributions: (I) Conception and design: PRB Evora, S Li; (II) Administrative support: PRB Evora; (III) Provision of study materials or patients: PRB \\ Evora, S Li; (IV) Collection and assembly of data: S Li; (V) Data analysis and interpretation: All authors; (VI) Manuscript writing: All authors; (VII) \\ Final approval of manuscript: All authors. \\ Correspondence to: Paulo Roberto Barbosa Evora. Department of Surgery and Anatomy of Ribeirao Preto Medical School FMRP-USP, University \\ of São Paulo, São Paulo, Brazil. Hospital das Clínicas da FMRP-USP, Av. Bandeirantes, 3900 - Campus Universitario, Monte Alegre 14048-900, \\ Ribeirao Preto, Sao Paulo, Brazil. Email: prbevora@gmail.com.
}

\begin{abstract}
Cardiac disease (CD) and oncologic disease (OD) are among the most lethal diseases. Both share common risk factors and as a consequence, there are a substantial number of patients who need surgeries for problems related to both diseases. Treatments for OD should start as soon as possible, as the disease can progress and disseminate, reducing life expectancy for patients. At times, heart problems may need cardiac surgery (CS), which are sophisticated and peculiar, at many times needing a machine to do the lung and the heart function as the surgeon does his job. This is called cardiopulmonary bypass (CPB), a procedure that is known to be related to inflammation and immunosuppression syndromes, that could lead the cancer disease to disseminate. There is little information on this subject in the literature so, in this narrative review, we have made a literature review, trying to address whether this theoretical worry confirms at evidencebased medicine. We also described some considerations regarding the use of devices like Cell Saver ${ }^{\circledR}$ and autotransfusion in oncologic patients. Further, we have taken some considerations about what care should be taken when facing situations with patients of different stages of OD needing CS and what should be discussed multidisciplinary aiming a treatment that best fits patient's life-expectancy and clinical status.
\end{abstract}

Keywords: Neoplasms; thoracic surgery; cardiopulmonary bypass (CPB)

Received: 24 July 2020. Accepted: 11 September 2020.

doi: $10.21037 /$ ccts-20-129

View this article at: http://dx.doi.org/10.21037/ccts-20-129

\section{Introduction}

Cardiac diseases (CD) and cancer are among the ten most frequent causes of death in the world (1). Both share many risk factors, and so, many oncologic patients have concurrent CD. As within the general population, when looking closely at the noncancer causes of death in patients with an oncologic disease (OD), heart disease is still the first one (2). As so, it is reasonable that some patients with malignancy may need a cardiac intervention, including cardiac surgery (CS). Besides, with the progressive increment in survival rates seen in cancer treatment in the past years $(3,4)$, part of then related to de development of modern therapeutics like molecular mutations targeting, immunotherapy, and cellular therapy, it is reasonable to expect increases in the number of people needing CS.

When facing cancer, time can be an urgent matter. As the treatment delays, the disease can progress and disseminate, worsening survival rates. However, many of the treatments used in cancer (chemotherapy, radiotherapy, immunotherapy, molecular target-therapy) can be toxic to the heart, worsening a coexistent CD (5-7). Due to this, in some selected cases, CS may be required before oncologic treatment.

Between the possible CS, some may need undergoing 


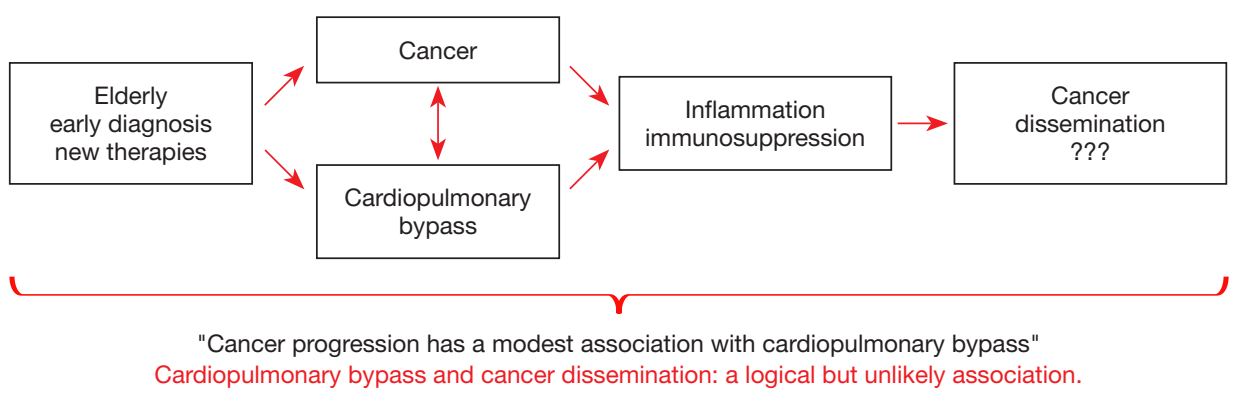

Figure 1 Cancer progression and cardiopulmonary dissemination (Visual Abstract).

a cardiopulmonary bypass $(\mathrm{CPB})$, a procedure in which the patient's heart and lungs are temporarily bypassed and supplanted by machines $(8,9)$. CPB is known to lead not only to a systemic inflammatory state but also to an immunosuppression one (10-12). So, theoretically, this could allow cancer to spread and recur (13). This relation is still unclear despite the advances in cardiac and oncologic treatments and the increase in publications about these themes.

Literature several questions occur when confronted with this problem. (I) Will the operative threat be more significant because the affected person has cancer? (II) Will the neoplastic disease enable sufficiently lengthy survival for the patient to revel in the result of the operation? (III) If cancer has been diagnosed recently, is it higher to the first function on the coronary heart or wait until the tumor has been treated? (IV) Will the systemic inflammatory response that frequently happens after surgery irritate the course of cancer? (V) Might there be some complications with the use of antithrombotic treatment? (14).

There is not any information that offers definitive evidence to these questions. Therefore, standards critiques of the international literature are extremely relevant justifying the "rationale" of the present text that are illustrated in the Visual Abstract (Figure 1).

\section{CPB related SIRS and immunosuppression:}

$\mathrm{CPB}$ is known to cause a transitory immunosuppression state by the elevation of cytokines (mainly IL-10 and TGF- $\beta$ ), leading to negative feedback of immunologic response mediated by T-cells $(12,15)$. As so, it seems coherent to think that this immunosuppressor effect may compromise the capacity of atypical and cancerous cells, leading to its dissemination.
Surgical applications of CPB started in the '50s. From that time on, many were the organic dysfunctions described in patients undergoing the procedure (12). The primary proposed mechanism seems to be related to an increase in capillary permeability, consequently leading to interstitial edema and impairing organs such as lungs, liver, and kidneys (16). Concurrently, there is an activation of the complement system's proteins, coherent with the systemic inflammatory state seen in these patients. Sometimes there can be an exaggerated inflammatory response, which we call Systemic Inflammatory Reaction State Syndrome (SIRS) (16).

Nowadays, CPB related SIRS is known to be triggered by a multifactorial cause, mainly divided into two phases: acute and late. In the acute phase, the blood contact with non-endothelial cells leads to molecular release, including anaphylatoxins activated by the complement system, causing upregulation of pro-inflammatory cytokines like IL-1, IL-6, TNF-alpha, increasing the adhesion of neutrophils to myocytes and endothelial cells $(10,15)$. They act synergically, stimulating the production of other cytokines by monocytes and leucocytes (IL-6 and IL-8). The reperfusion phenomena following $\mathrm{CPB}$ also upregulates the IL-1 and TNF-alpha expression by microvascular endothelial cells, causing a myocardial disfunction (17). Besides their direct role, the interleukins also trigger inflammatory cascades activations.

Simultaneously, we have inhibition of Toll-like receptors (TLR) activation (18) mediating an immunosuppression state. So, in CPB, we have activation of both: proinflammatory and anti-inflammatory cytokines. The antagonism of SIRS is called Compensatory Antiinflammatory Reaction Syndrome (CARS) $(16,19)$. In severe SIRS, there is an exacerbation of the innate proinflammatory system, causing organic dysfunction, while at CARS, there is an inhibition of the adaptative immunity 
and apoptotic system through the production of antiinflammatory cytokines (e.g., IL-4 and IL-10). Antiinflammatory exacerbation leads to immunoparalysis, impaired cicatrization, a propensity to infections, and also to organic dysfunction (20). Genetic features mediate both SIRS and CARS, and the host environmental exposure may trigger then, with antagonistic phenotypes of organic reaction in patients with severe injuries (10).

As CPB is associated with SIRS and CARS, leading to inflammatory and immunosuppression state at the same time, it seems acceptable that it could predispose to tumor dissemination (21). Two are the primary mechanism proposed: tumor cell hematogenic dissemination from the reservatory thought the arterial cannula and disbalance of the inhibition of tumor cells by the host immunity.

\section{Mechanistic biomarkers of cardiovascular disease and cancer}

Cardiovascular diseases and cancer share several common pathophysiological mechanisms for the incidence and progression of the disease. In the recently published review by Narayan et al. (22), Several markers common to both diseases were highlighted, in an attempt to understand the relationship between cardiovascular disease and cancer through fundamental biological processes common to CVD and cancer, including inflammation, cell proliferation, resistance to death neurohormonal stress, angiogenesis, and genomic instability. Papers of Interleukin 6, highly sensitive C-reactive protein (hsCRP), interleukin-33, suppression of tumorigenicity, galectin-3, growth differentiation factor 15 (GDF-15), cardiac troponin T, neurohormones such as NTproBNP were reviewed. and regional intermediate pro-atrial natriuretic peptide (MR-proANP), neurotensin (NTS), placental growth factor (PlGF), and clonal hematopoiesis of undetermined potential (CHIP). As the era of personalized medicine advances, new biomarkers are expected to be used to inform and improve the prognosis of the disease in cardiovascular diseases and cancer. Understanding the role of these biomarkers can additionally inform the application of therapies. An example of this is Canakinumab, an antiIL1b monoclonal antibody, which improved the secondary prevention of important cardiovascular events in patients with elevated highly sensitive C-reactive protein (hsCRP) after myocardial infarction (IM) (23-25) and showed a reduction in incident lung cancer, suggesting potential cancer benefit through an anti-inflammatory therapeutic intervention (26).

\section{Surgical related mortality risk in oncologic patients}

It seems like there is no significant increase in surgical related mortality for patients with OD undergoing CS with $\mathrm{CPB}$, either in hematologic malignancies and solid cancers $(14,27,28)$. Even when looking at heart transplantation, some experienced groups advocate that, in selected groups, the 1 -year survival rate is comparable to overall rates $(70 \%$ vs. $80 \%)(29,30)$.

\section{Surgical morbidity}

Despite not having a higher rate of early mortality, OD patients undergoing CS have an increased risk of morbidity $(31,32)$. Mainly decurrent of a higher rate of blood transfusion, atrial fibrillation at post-operatory, pneumonia, sepsis, reintubation rate, and even cerebrovascular accidents.

\section{Minimally invasive cardiovascular procedures in oncologic patients}

Minimally invasive procedures rapidly developed in the last decades, allowing them to make aortic valve treatments without open surgery. Guided by $\mathrm{X}$-ray radioscopy visualization, it is possible to make valvuloplasty by balloon inflation through a femoral vessel's catheter insertion. Even some valve replacements can be done by a minimally invasive whey, like transcatheter valve replacements (33) or even transapical mitral implants (34).

There are still small data regarding these procedures in oncologic patients, but even though high material costs and the need for specialized teams, the reduced recovery time and lower perioperative risks, when compared to open surgeries, are features to be considered. Even palliative patients can benefit from aortic balloon valvuloplasty if indicated (35).

\section{CPB and risk of new cancers}

By following 48,009 patients who undergo CS due to coronary artery disease (CAD), a multicentric cohort study (36) found an incidence of $6.8 \%$ of cancer at longterm follow-up. They also looked at the association of cancer development and $\mathrm{CPB}$ use and found that despite a marginally higher incidence $(7.2 \%$ vs. $5.8 \%)$, it was not statistically significant. And so, concluded that even if there is an association between CPB and cancer development 
that he could not prove, it is probably a little one. Hence, more research is needed to establish if transitory immunosuppression related to $\mathrm{CPB}$ may or not promote pre-existent cancer cell growth or dissemination.

\section{CPB in OD patients}

Long term follow-up of patients known to have OD who had a CS preceding the start of oncologic treatment also did not show a significant difference between those undergoing $\mathrm{CPB}$ and those who did not (23). Rates of oncologic recurrence, progression, or death were all similar between groups.

\section{The urge for cancer therapy}

Cancer treatment should be started as soon as possible after diagnostic confirmation, in most cases, before a CS. Only when facing patients at a high risk of major adverse cardiovascular events, the surgical procedure necessity superimposes the start of OD treatment (37). When facing patients with acute myocardial infarction, cardiac insufficiency, symptomatic cardiac valve disease, or risk of aneurysm rupture, one should consider CS before OD treatment.

It is important to remember that radiotherapy can lead to fibrosis and the development of adherence, which may put patients at more risks at surgical procedures, predisposing to vascular iatrogenic lesions and dehiscence. Furthermore, the liberation of chemotherapy or immunotherapy doses may also contribute to CD decompensations, by reducing ventricular ejection fraction by cardiotoxicity or autoimmune myocarditis.

\section{Rapid cancer progression, recurrence, and CPB}

Sometimes we see advanced stage OD cases, with a rapid cancer progression after a CPB (21). Even though, when comparing these patients with the ones going palliative treatments, the mortality is similar. So, maybe this rapid progression may not be related to the procedure itself. Concomitantly, there is no statistically significant difference in survival rates when comparing CS in patients who have treated cancer ten or more years before, with equivalent aged populations.

There is controversy in literature if the morbimortality and tumor recurrence related to CS can be higher in oncologic patients (32) ongoing extracorporeal circulation
(ECC). About this fact, it seems like the time between the cancer diagnosis and CS also has a role in survival, with the best outcomes obtained when operating patients who had diagnosticated malignancy for more than two years (perhaps inferring a more indolent OD) (32).

\section{Combined surgeries}

Sometimes, given the duality of what urges most, patients are simultaneously operated for cancer and the CD $(38,39)$. Despite feasible, the benefit of combined surgery is still controversial as there is an increased risk of pulmonary edema from $\mathrm{CPB}$ and bleeding by the heparinization required by CS. So, a rigorous selection of candidates must be made.

\section{The use of Cell Saver ${ }^{\circledR}$ and autotransfusion in cancer patients}

About the use of autotransfusion equipment such as Cell Saver ${ }^{\circledR}$ in cancer surgeries, Akchurin et al. (40) described eight oncologic patients who underwent operations using CBP and Cell Saver. All of the patients survived the surgery and were alive one year after. After each operation, researchers analyzed the filter system searching for neoplastic cells. Atypical cells and microthrombi were found on the physiological surface of the CPB arterial filters with 20 microns holes. On the outer surface of the filters and in the washed red blood cells, tumor cells were absent. The authors concluded that the potential possibilities of hematogenous metastasis when using special filters is minimal, but further investigation and the design of more effective filters for oncology patients are required.

\section{CBP and some most frequent associate cancer}

\section{Lung cancer}

Muralidaran et al. (41) in 2011 carried out a systematic review of the literature on lung resections in non-small cell lung cancer using cardiopulmonary bypass using PubMed. From January 1, 1990, to December 31, 2010, a total of 20 articles were found that fit the selection criteria. They observed that the survival of these patients is higher when the use of $\mathrm{CPB}$ is planned, compared to surgeries whose $\mathrm{CPB}$ was used in an emergency or an unplanned manner. The unplanned use of $\mathrm{CPB}$ was considered as a prognostic factor for worse long-term survival. 


\section{CPB and renal cell carcinoma and adrenocortical carcinoma}

Among urogenital malignancies, adrenocortical carcinoma and renal cell carcinoma are highly aggressive, and their treatment is surgical. These tumors occasionally extend through the inferior vena cava and affect the right atrium, requiring the use of $\mathrm{CPB}$ for resection.

In 2015, Nguyen et al. (42) conducted a cohort study of 362 patients using data from 22 institutions in Europe and the United States on the impact of cardiopulmonary bypass on global and specific survival in patients undergoing level III-IV nephrectomy and tumor thrombectomy. Patients operated on using CPB did not observe a statistically significant difference in overall survival compared to patients operated without using $\mathrm{CPB}$.

In 2019, Chaud et al. (43) carried out a retrospective cohort study with nine cases of renal and adrenocortical tumors with invasion of the right atrium through the inferior vena cava operated using $\mathrm{CPB}$ and deep hypothermic circulatory arrest, performed at our service. In the review of the existing literature, no publications were found directly correlating the type of neoplasia with the possible spread caused or favored by CPB.

\section{CBP and digestive system cancer}

In the PubMed survey (accessed 05/26/2020) using the words CEC, Cancer, gastric, digestive, colorectal, only 1 article was found related to the use of $\mathrm{CPB}$ in a patient with gastrointestinal cancer. Platell (44) compared the outcome of patients with colorectal cancer who underwent cardiac surgery using $\mathrm{CPB}$ and those who did not. The 5-year survival rate specifically related to cancer was significantly lower in patients undergoing CPB surgery. However, considering only patients undergoing potentially curative resection, that is, excluding patients with stage IV cancer, there was no significant difference in the specific cancer survival rate. The author concludes that it was not possible to determine a causal relationship between the use of $\mathrm{CPB}$ in a patient with colorectal cancer and survival.

\section{CBP and haematological cancer}

In a 2014 text, Plumereau et al. (27) concluded that the use of CPB surgery does not increase long-term mortality in patients with hematological neoplasia, and there does not appear to be a risk of malignancy progressing to a more aggressive form after $\mathrm{CPB}$ cardiac surgery. He attributes these results to the routine use of leukocyte depletion filters and the cell protection technique during $\mathrm{CPB}$ surgery.

\section{A logical but unlikely association}

Despite those proposed mechanisms that could increase tumor dissemination when using $\mathrm{CPB}$, it seems that the survival of cancer patients who undergo cardiac surgery is more related to the progression of the tumor than the surgical procedure (27). CPB also does not seems to be a trigger that changes OD to a more aggressive form. The use of leukocyte depletion filters and cellular protection techniques employed at $\mathrm{CPB}$, known to reduce the risk of hematologic malignancy dissemination, may have some role at that.

When looking at mortality causes in OD patients, CD is the most frequent noncancer cause of death (2). So, it seems reasonable that $\mathrm{CS}$ with or without $\mathrm{CPB}$ remains within the arsenal of therapies for this population, especially in treated or stable malignancy cases. Principally, given that there is no definitive proof that $\mathrm{CS}$ with $\mathrm{CPB}$ can either increase dissemination or survival (45).

\section{Conclusions}

In this article, we have pointed out the main mechanisms and principles that justify the worry of cancer spread and survival rates reduction in oncologic patients undergoing CS with CPB. Regardless of the public health importance and shared risk factors of both CD and cancer, publications about the subject are still scarce. Although the theoretical risk of cancer dissemination by $\mathrm{CPB}$, it is not easy to prove it, as we can see by the articles already published about this theme. Overall, in our opinion, some extra care should be taken when considering CS in cancer patients. For patients with a remitted OD, given the potential life expectancy with new treatments, it seems like we are close to a consensus that CS should be promptly considered between the hall of treatment option, of course, following $\mathrm{CD}$ guidelines for his pathology. At high stage OD, there is a particular propensity to search for alternative non-surgical treatments as the morbimortality in CS is not negligible. For the remaining scenarios, a multidisciplinary approach pointing out oncologic, cardiac, and surgical teams' main worries can aid in decision making. The discussion should focus on whether the patient's significant risk of death in the short and mid-term would be related to CS, OD, or 
CD. In a logical reasoning based on the paradigm "a logical but unlikely association", one can speculate why CPB is not associated with the spread of cancerous disease. $\mathrm{CPB}$ introduces at least three variables: massive heparinization, continuous flow and temperature variation. But, these speculative variables are not strong enough to confront the doubts mentioned in the title of this review: myth, reality, enigma, puzzle?

\section{Concluding remarks}

* Cardiac and OD are among the most lethal diseases. Both share common risk factors and as a consequence, there are a substantial number of patients who need surgeries for problems related to both diseases

* At times, heart problems may need cardiac surgery, that is known to be related to inflammation and immunosuppression syndromes, that could lead the cancer disease to disseminate.

* This relation is still unclear despite the advances in cardiac and oncologic treatments and the increase in publications about these themes.

* The discussion should focus on whether the patient's significant risk of death in the short and mid-term would be related to cardiac surgery, cardiovascular disease or the OD.

* The paradigm "a logical but unlikely association" (CPB associated with the spread of cancerous disease), remains a matter of speculation.

CPB introduces at least three variables: massive heparinization, continuous flow and blood temperature controlled variation. However, these speculative variables are not strong enough to confront the doubts mentioned in the title of this review: myth, reality, enigma, puzzle?

\section{Acknowledgments}

Funding: None.

\section{Footnote}

Provenance and Peer Review: This article was commissioned by the Guest Editors (Andrea Dell'Amore and Nizar Asadi) for the series "Mechanical Extracorporeal CardioRespiratory Supports in General Thoracic Surgery" published in Current Challenges in Thoracic Surgery. The article was sent for external peer review organized by the Guest Editors and the editorial office.
Conflicts of Interest: The authors have completed the ICMJE uniform disclosure form (available at http:// dx.doi.org/10.21037/ccts-20-129). The series "Mechanical Extracorporeal Cardio-Respiratory Supports in General Thoracic Surgery" was commissioned by the editorial office without any funding or sponsorship. The authors have no other conflicts of interest to declare.

Ethical Statement: The authors are accountable for all aspects of the work in ensuring that questions related to the accuracy or integrity of any part of the work are appropriately investigated and resolved.

Open Access Statement: This is an Open Access article distributed in accordance with the Creative Commons Attribution-NonCommercial-NoDerivs 4.0 International License (CC BY-NC-ND 4.0), which permits the noncommercial replication and distribution of the article with the strict proviso that no changes or edits are made and the original work is properly cited (including links to both the formal publication through the relevant DOI and the license). See: https://creativecommons.org/licenses/by-nc-nd/4.0/.

\section{References}

1. WHO I Causes of death 2020 [cited 2020 May 24]. Available online: https://www.who.int/gho/mortality_ burden_disease/causes_death/en/

2. Zaorsky NG, Churilla TM, Egleston BL, et al. Causes of death among cancer patients. Ann Oncol 2017;28:400-7.

3. U.S. National Institute of Health NCI. SEER Cancer Statistics Review, 1975-2007 2010. Available online: https://seer.cancer.gov/archive/csr/1975_2007/

4. Siegel RL, Miller KD, Jemal A. Cancer statistics, 2020. CA Cancer J Clin 2020;70:7-30.

5. Babiker HM, McBride A, Newton M, et al. Cardiotoxic effects of chemotherapy: A review of both cytotoxic and molecular targeted oncology therapies and their effect on the cardiovascular system. Crit Rev Oncol Hematol 2018;126:186-200.

6. Palaskas N, Lopez-Mattei J, Durand JB, et al. Immune Checkpoint Inhibitor Myocarditis: Pathophysiological Characteristics, Diagnosis, and Treatment. J Am Heart Assoc 2020;9:e013757.

7. Cheng H, Force T. Molecular Mechanisms of Cardiovascular Toxicity of Targeted Cancer Therapeutics. Circ Res 2010;106:21-34.

8. Gravlee G. Cardiopulmonary bypass: principles and 
practice. Wolters Kluwer Health/Lippincott Williams \& Wilkins, 2008.

9. Sarkar M, Prabhu V. Basics of cardiopulmonary bypass. Indian J Anaesth 2017;61:760.

10. Gentile LF, Cuenca AG, Efron PA, et al. Persistent inflammation and immunosuppression. J Trauma Acute Care Surg 2012;72:1491-501.

11. Evora PRB, Bottura C, Arcêncio L, et al. Key Points for Curbing Cardiopulmonary Bypass Inflammation. Acta Cir Bras 2016;31:45-52.

12. Moura HV, Pomerantzeff PMA, Gomes WJ. Síndrome da resposta inflamatória sistêmica na circulação extracorpórea: papel das interleucinas. Rev Bras Cir Cardiovasc 2001;16:376-87.

13. Évora PRB, Albuquerque AAS, Nadai TR,et al.The cardiopulmonary bypass and cancer dissemination puzzle. Acta Cir Bras 2018;33:1037-42.

14. Azpitarte J. Cardiac Surgery in the Cancer Patient. Rev Española Cardiol (English Ed 2008;61:349-51.

15. Binkowska AM, Michalak G, Słotwiński R. Review paper Current views on the mechanisms of immune responses to trauma and infection. Cent Eur J Immunol 2015;40:206-16.

16. Sauaia A, Moore FA, Moore EE. Postinjury Inflammation and Organ Dysfunction. Crit Care Clin 2017;33:167-91.

17. Parker DJ, Cantrell JW, Karp RB, et al. Changes in serum complement and immunoglobulins following cardiopulmonary bypass. Surgery 1972;71:824-7.

18. Li YP, Huang J, Huang S, et al. The compromised inflammatory response to bacterial components after pediatric cardiac surgery is associated with cardiopulmonary bypass-suppressed Toll-like receptor signal transduction pathways. J Crit Care 2014;29:312.e7312.e13.

19. Moore KL, Dallwy AF, Agur AMR. Clinically oriented anatomy. Wolters Kluwer Health/Lippincott Williams \& Wilkins, 2014.

20. Tschoeke SK, Ertel W. Immunoparalysis after multiple trauma. Injury 2007;38:1346-57.

21. Hasegawa S, Otake Y, Bando T, et al. Pulmonary dissemination of tumor cells after extended resection of thyroid carcinoma with cardiopulmonary bypass. J Thorac Cardiovasc Surg 2002;124:635-6.

22. Narayan V, Thompson EW, Demissei B, et al. Mechanistic Biomarkers Informative of Both Cancer and Cardiovascular Disease. J Am Coll Cardiol 2020;75:2726-37.

23. Ridker PM, Everett BM, Thuren T, et al.
Antiinflammatory Therapy with Canakinumab for Atherosclerotic Disease. N Engl J Med 2017;377:1119-31.

24. Ridker PM, Howard CP, Walter V, et al. Effects of Interleukin- $1 \beta$ Inhibition With Canakinumab on Hemoglobin A1c, Lipids, C-Reactive Protein, Interleukin-6, and Fibrinogen. Circulation 2012;126:2739-48

25. Ridker PM, MacFadyen JG, Everett BM, et al. Relationship of C-reactive protein reduction to cardiovascular event reduction following treatment with canakinumab: a secondary analysis from the CANTOS randomised controlled trial. Lancet 2018;391:319-28.

26. Ridker PM, MacFadyen JG, Thuren T, et al. Effect of interleukin- $1 \beta$ inhibition with canakinumab on incident lung cancer in patients with atherosclerosis: exploratory results from a randomised, double-blind, placebocontrolled trial. Lancet 2017;390:1833-42.

27. Plumereau F, Pinaud F, Roch A, et al. Do patients with haematological malignancy who need cardiopulmonary bypass have a short-term higher mortality or a higher chance of disease progression? Interact Cardiovasc Thorac Surg 2014;19:474-8.

28. Suzuki S, Usui A, Yoshida K, et al. Effect of Cardiopulmonary Bypass on Cancer Prognosis. Asian Cardiovasc Thorac Ann 2010;18:536-40.

29. Dunning JJ, Mullins PA, Scott JP, et al. Cardiac transplantation and cancer. Am J Cardiol 1991;67:327.

30. Edwards BS, Hunt SA, Fowler MB, et al. Cardiac transplantation in patients with preexisting neoplastic diseases. Am J Cardiol 1990;65:501-4.

31. Chan J, Rosenfeldt F, Chaudhuri K, et al. Cardiac Surgery in Patients with a History of Malignancy: Increased Complication Rate but Similar Mortality. Heart Lung Circ 2012;21:255-9.

32. Carrascal Y, Gualis J, Arévalo A, et al. [Cardiac surgery with extracorporeal circulation in cancer patients: influence on surgical morbidity and mortality and on survival]. Rev EspCardiol 2008;61:369-75.

33. Bax JJ, Delgado V, Hahn RT, et al. Transcatheter Aortic Valve Replacement. JACC Cardiovasc Imaging 2020;13:124-39.

34. Wu IY, Barajas MB, Hahn RT. The MitraClip ProcedureA Comprehensive Review for the Cardiac Anesthesiologist. J Cardiothorac Vasc Anesth 2018;32:2746-59.

35. Balanescu SM, Balanescu DV, Donisan T, et al. The Onco-cardiologist Dilemma: to Implant, to Defer, or to Avoid Transcatheter Aortic Valve Replacement in Cancer Patients with Aortic Stenosis? "Curr Cardiol Rep 
2019;21:83.

36. Pinto CA, Marcella S, August DA, et al. Cardiopulmonary bypass has a modest association with cancer progression: a retrospective cohort study. BMC Cancer 2013;13:519.

37. Lorusso R, Vizzardi E, Johnson DM, et al. Cardiac surgery in adult patients with remitted or active malignancies: a review of preoperative screening, surgical management and short- and long-term postoperative results. Eur J Cardiothorac Surg 2018;54:10-8.

38. Dyszkiewicz W, Jemielity MM, Piwkowski CT, et al. Simultaneous lung resection for cancer and myocardial revascularization without cardiopulmonary bypass (offpump coronary artery bypass grafting). Ann Thorac Surg 2004;77:1023-7.

39. Miller DL, Orszulak TA, Pairolero PC, et al. Combined operation for lung cancer and cardiac disease. Ann Thorac Surg 1994;58:989-93.

40. Akchurin RS, Davidov MI, Partigulov SA, et al. Cardiopulmonary Bypass and Cell-Saver Technique in Combined Oncologic and Cardiovascular Surgery. Artif

doi: $10.21037 /$ ccts-20-129

Cite this article as: Siyuan L, Wada DT, Evora PRB. Cardiopulmonary bypass and cancer dissemination and progression: myth reality, enigma, puzzle? Curr Chall Thorac Surg 2020.
Organs 1997;21:763-5.

41. Muralidaran A, Detterbeck FC, Boffa DJ, et al. Long-term survival after lung resection for non-small cell lung cancer with circulatory bypass: A systematic review. J Thorac Cardiovasc Surg 2011;142:1137-42.

42. Nguyen HG, Tilki D, Dall'Era MA, et al. Cardiopulmonary Bypass has No Significant Impact on Survival in Patients Undergoing Nephrectomy and Level III-IV Inferior Vena Cava Thrombectomy: MultiInstitutional Analysis. J Urol 2015;194:304-8.

43. Chaud F, Junior ST, Bassetto S, et al. Right Atrium Tumor Extension Through the Inferior Vena Cava. Considerations About Nine Cases Operated Under Cardiopulmonary Bypass. Braz J Cardiovasc Surg 2019;34:723-8.

44. Platell C. Influence of cardiopulmonary bypass surgery on cancer-specific survival rate of patients with colorectal cancer. Dis Colon Rectum 1998;41:1371-5.

45. Braile DM, Evora PRB. Cardiopulmonary Bypass and Cancer Dissemination: A Logical But Unlikely Association. Braz J Cardiovasc Surg 2018;33:I-II. 